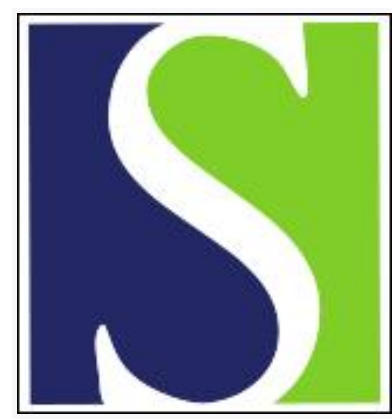

Scand J Work Environ Health 2003;29(5):378-387

https://doi.org/10.5271/sjweh.744

Issue date: Oct 2003

Cytogenetic and morphologic subgroups of myelodysplastic syndromes in relation to occupational and hobby exposures by Albin M, Björk J, Welinder $H$, Tinnerberg $H$, Mauritzson N, Billström R, Strömberg U, Mikoczy Z, Johansson B, Ahlgren T, Nilsson P-G, Mitelman F, Hagmar L

Affiliation: Department of Occupational and Environmental Medicine, Lund Univsersity Hospital, SE-221 85 Lund, Sweden. maria.albin@ymed.lu.se

Key terms: benzene; chronic myelomonocytic leukemia; cytogenetic subgroup; epidemiology; extremely low-frequency magnetic fields; farming; hobby exposure; karyotype; morphologic subgroup; myelodysplasia; myelodysplastic syndrome; occupational exposure; organic solvent; risk factor

This article in PubMed: www.ncbi.nlm.nih.gov/pubmed/14584518 


\title{
Cytogenetic and morphologic subgroups of myelodysplastic syndromes in relation to occupational and hobby exposures
}

\author{
by Maria Albin, MD, ${ }^{1}$ Jonas Björk, PhD, ${ }^{1}$ Hans Welinder, PhD, ${ }^{1}$ Håkan Tinnerberg, PhD, ${ }^{1}$ Nils Mauritzson, \\ MD, ${ }^{2}$ Rolf Billström, MD, ${ }^{2}$ Ulf Strömberg, PhD, ${ }^{1}$ Zoli Mikoczy, MSc, ${ }^{1}$ Bertil Johansson, MD, ${ }^{3}$ Tomas \\ Ahlgren, MD, ${ }^{4}$ Per-Gunnar Nilsson, MD, ${ }^{2}$ Felix Mitelman, MD, ${ }^{3}$ Lars Hagmar, $M D^{1}$
}

\begin{abstract}
Albin M, Björk J, Welinder H, Tinnerberg H, Mauritzson N, Billström R, Strömberg U, Mikoczy Z, Johansson B, Ahlgren T, Nilsson P-G, Mitelman F, Hagmar L. Oytogenetic and morphologic subgroups of myelodysplastic syndromes in relation to occupational and hobby exposures. Scand J Work Environ Health 2003;29(5):378-387.
\end{abstract}

\begin{abstract}
Objectives This study investigated the association between occupational and hobby exposure and the risk of myelodysplastic syndromes (MDS) while focusing on differential patterns of clonal chromosome aberrations and morphologic subgroups.

Methods A case-referent study was conducted with 330 MDS patients investigated cytogenetically in 19761993 (cases) and matched referents. Telephone interviews with either the person or a next-of-kin were used. The participation rate of the cases and referents was $85 \%$ and $60 \%$, respectively. Information was obtained from the next-of-kin more often for the cases $(88 \%)$ than for the referents $(26 \%)$. Occupational hygienists assessed the exposure using interview data on worktasks and hobbies. Associations with disease risk were evaluated for 10 exposures with a logistic regression analysis.

Results The investigated exposures were generally not associated with cytogenetically abnormal MDS. Effect estimates for specific cytogenetic or morphologic subgroups were generally imprecise. Occupational exposure to extremely low-frequency magnetic fields (EMF) was associated with MDS with a normal karyotype [odds ratio (OR) 2.0, 95\% confidence interval (95\% CI) 1.0-4.0]. The exposure-response association was consistent for intensity but inconclusive for duration. A decreased risk was observed for MDS, irrespective of karyotypic pattern, among farmers and farmhands (OR 0.53, 95\% CI 0.35-0.81).

Conclusions Cytogenetically abnormal MDS was generally not associated with occupational or hobby exposure to known or suspected genotoxic agents. However, exposure prevalences and intensities were low for several agents. An association was suggested between occupational exposure to EMF and MDS with a normal karyotype. Biases due to differential information quality and selective participation cannot be ruled out.
\end{abstract}

Key terms benzene, chronic myelomonocytic leukemia, epidemiology, extremely low-frequency magnetic fields, farming, karyotype, myelodysplasia, organic solvents, risk factors.

Myelodysplastic syndromes (MDS) are a group of hematologic malignancies that are heterogeneous with respect to gender, age distribution, involved cell lines, risk of transformation to leukemia, and survival (1-3). Crude incidences between 3 and 13 per $100000 /$ person-year have been reported for different populations, all with steeply increasing incidence rates at older ages (4-6). Risk factors for MDS are previous chemo- or radiotherapy and exposure to benzene (7-9). Associations with tobacco smoking have been observed or indicated in some studies (10-14) but not in others (15-18). Although regular personal usage of hair dye has been linked to MDS (11, $18,19)$, the evidence of an association is weak overall (20). Other exposures suggested as risk factors include organic solvents besides benzene, extremely low-frequency magnetic fields (EMF), gasoline and diesel fuel,

1 Department of Occupational and Environmental Medicine, Lund University Hospital, Lund, Sweden.

2 Department of Internal Medicine, Division of Hematology, Lund University Hospital, Lund, Sweden.

3 Department of Clinical Genetics, Lund University Hospital, Lund, Sweden.

4 Division of Hematology, Malmö University Hospital, Malmö, Sweden.

Reprint requests to: Dr Maria Albin, Department of Occupational and Environmental Medicine, Lund University Hospital, SE-221 85 Lund, Sweden. [E-mail: maria.albin@ymed.lu.se] 
and agricultural exposures like grain dust, fertilizers, pesticides, and livestock or poultry $(11,13,15,21-23)$.

MDS after radiotherapy or chemotherapy including alkylating agents are accompanied by complex karyotypes and partial or complete losses of chromosomes 5 or 7 more often than de novo MDS $(7,8)$. In addition, the morphological subgroup refractory anemia with excess blasts is overrepresented among therapy-related MDS (1). One can hypothesize that genotoxic agents, present in, for example, occupational or hobby activities, may primarily induce MDS with characteristic karyotypic abnormalities or characteristic morphological features, but few MDS studies have addressed this issue. An association has been suggested between exposure to pesticides and organic solvents and morphological or cytogenetic subgroups of MDS with a poor prognosis (21). Furthermore, a recent report indicated stronger effects of several combined occupational and environmental exposures on cytogenetically abnormal MDS than on normal MDS; however, no associations were established with specific exposures (24).

The aim of our study was to investigate associations between a broad range of occupational and hobby exposures and cytogenetic and morphological subgroups of MDS.

\section{Participants and methods}

\section{Cases}

The study, approved by the Ethics Committee of Lund University, was based on a series of 389 consecutively diagnosed cases of adult MDS from southern Sweden, cytogenetically analyzed between 1976 and 1993 at the Department of Clinical Genetics, Lund. The Department performs cytogenetic investigations for persons with suspect MDS from the catchment area of the Lund University Hospital, as well as from other parts of southern Sweden. All referrals for cytogenetic investigations are made within the public health care system. In the catchment area of the Lund University Hospital, referrals for cytogenetic investigations were routinely used in the diagnostic evaluation of hematologic malignancies throughout the study period; this use implies a high coverage of incident cases. The coverage for other parts of southern Sweden is less complete. All the cytogenetic investigations were performed before treatment on bone marrow or peripheral blood samples in a standardized fashion. In short, the cells were adjusted to a concentration of $10^{6} / \mathrm{ml}$ and cultured for 24 and 48 hours in McCoy's 5A medium supplemented with $20 \%$ fetal calf serum, L-glutamine, and antibiotics, and the chromosome preparations were banded by trypsin-Giemsa. The definition and description of clonal abnormalities, followed the recommendations of the International System for Human Cytogenetic Nomenclature (25) throughout the study period. In general, 25 metaphases were analyzed. The cytogenetic investigation was considered a failure if less than 10 metaphases could be studied, unless a cytogenetically abnormal clone was identified. Three hematologists reviewed the medical records to verify the morphological grouping according to the French-American-British classification (2). This review, as well as the cytogenetic investigation, was blind with regard to exposure. A detailed description of the present MDS series and a thorough investigation of the association with tobacco smoking have been presented elsewhere $(10,26)$.

The participants were retrospectively enrolled in the study in 1994. Out of the 389 eligible persons, interview information was obtained for 330 (85\% participation rate) (table 1), including 104 with refractory anemia, 34 with refractory anemia with ringed sideroblasts, 115 with refractory anemia with excess blasts or refractory anemia with excess blasts in transformation, 58 with chronic myelomonocytic leukemia, and 19 with unclassifiable MDS. Those for whom interview information could not be obtained $(\mathrm{N}=59)$ were slightly older at the time of the diagnosis (median age 75 years) and less often male (52\%) than the participants. The most common reasons for nonparticipation were "no relatives" $(55 \%)$ and "refusal by the respondent" (36\%). In the data analyses, cases were classified with respect to karyotype (normal, abnormal) (table 1). Abnormal karyotypes were further grouped according to the number of abnormalities (sole, two, or complex) and with respect to prognostic category as bad [(complex, $\operatorname{der}(1 ; 7)$, monosomy 7 , or $7 \mathrm{q}-)$ ], good (-Y, 5q-, or 20q- as sole anomaly), or intermediate (those not specified as good or bad). Specific clonal chromosome aberrations with sufficient numbers (minimum 5 cases) to permit analysis were $-3 /$ $3 \mathrm{p}-,-5 / 5 \mathrm{q}-$ (not sole), $-7 / 7 \mathrm{q}-/ \operatorname{der}(1 ; 7)(\mathrm{q} 10 ; \mathrm{p} 10),+8$, and $-12 / 12 \mathrm{p}-$.

\section{Referents}

Three referents were randomly selected by the Swedish National Bureau of Statistics (Statistics Sweden) from the study population of southern Sweden for each cytogenetically analyzed case, matched with respect to gender, age, and county of residence. Each referent was sampled from the population in the calendar year during which the corresponding case was diagnosed. We aimed at obtaining interview information for one randomly selected referent in each matched set. When a referent could not be interviewed, another referent from the matched set was selected. The participation rate of the referents was $60 \%$; 565 participants had to be selected to achieve satisfactory 1:1 matched sets, 
Table 1. Descriptive statistics for the cases with myelodysplastic syndromes (MDS) and their referents. $($ Med $=$ median, 10 th $=10$ th percentile, 90th $=$ 90th percentile)

\begin{tabular}{|c|c|c|c|c|c|c|c|c|c|c|c|c|c|c|c|c|c|c|}
\hline & \multicolumn{3}{|c|}{ Year of diagnosis } & \multicolumn{2}{|c|}{ Year of birth } & \multicolumn{3}{|c|}{$\begin{array}{l}\mathrm{Age}^{\mathrm{a}} \\
\text { (years) }\end{array}$} & \multicolumn{2}{|c|}{ Males } & \multicolumn{2}{|c|}{$\begin{array}{l}\text { Interviewed } \\
\text { in person }\end{array}$} & \multicolumn{2}{|c|}{ Smokers ${ }^{b}$} & \multicolumn{2}{|c|}{$\begin{array}{l}\text { Chemo- or } \\
\text { radiother- } \\
\text { apyc (inter- } \\
\text { view in- } \\
\text { formation) }\end{array}$} & \multicolumn{2}{|c|}{$\begin{array}{l}\text { Chemo- or radio- } \\
\text { therapy( inter- } \\
\text { view informa- } \\
\text { tion or medical } \\
\text { records) }\end{array}$} \\
\hline & Med & 10th & 90th & Med & 10th 90th & Med & 10th & 90th & $\mathrm{N}$ & $\%$ & $\mathrm{~N}$ & $\%$ & $\mathrm{~N}$ & $\%$ & $\mathrm{~N}$ & $\%$ & $\mathrm{~N}$ & $\%$ \\
\hline \multicolumn{19}{|l|}{$\begin{array}{l}\text { MDS with clonal chro- } \\
\text { mosome aberrations }\end{array}$} \\
\hline Cases (N=168) & 1987 & 1980 & 1992 & 1915 & 19031934 & 72 & 52 & 83 & 92 & 54.7 & 15 & 8.9 & 82 & 48.8 & 19 & 11.3 & 46 & 27.4 \\
\hline Referents (N=170) & 1987 & 1980 & 1992 & 1916 & 19041936 & 71 & 50 & 82 & 94 & 55.3 & 124 & 72.9 & 66 & 38.8 & 8 & 4.7 & - & . \\
\hline \multicolumn{19}{|l|}{$\begin{array}{l}\text { MDS with a normal } \\
\text { karyotype }\end{array}$} \\
\hline Cases (N=162) & 1988 & 1982 & 1993 & 1917 & 19041933 & 71 & 53 & 82 & 108 & 66.7 & 26 & 16.0 & 80 & 49.4 & 5 & 3.1 & 10 & 6.2 \\
\hline Referents (N=167) & 1988 & 1982 & 1992 & 1917 & 19041933 & 71 & 53 & 82 & 112 & 67.1 & 126 & 75.4 & 61 & 36.5 & 5 & 3.0 & - & . \\
\hline
\end{tabular}

${ }^{a}$ Age at the year of diagnosis for the cases and at the year of selection from the study population for the referents.

${ }^{b}$ Ever smoker during the 20 years before the diagnosis of the case. Six cases and eight referents had unknown smoking habits.

c Chemotherapy or radiotherapy (including treatment with isotopes) during the 20 years before the case diagnosis (36 cases, 10 referents) or at an unknown time (20 cases, 3 referents).

comprising 337 interviewed referents (table 1). The nonparticipating referents were older at the time of diagnosis (median 76 years) and less often male (56\%) than the participants. The most common reason for nonparticipation was "refusal by the respondent" (76\%).

\section{Information on exposure}

The eligible persons were contacted in 1995-1997 with a letter describing the purpose of the study and giving the main questions to be asked during the structured telephone interview. If the subject was deceased or too ill to participate, a next-of-kin was selected in the following order: spouse, parent, sibling, child. Spouses and children were the most frequently interviewed (>85\% of next-of-kin). Information had to be obtained from a next-of-kin much more often for the cases $(88 \%$ of the interviews) than for the referents (26\% of the interviews). The interviews were conducted by three occupational health nurses, who, for both ethical and practical reasons, had to be aware of the disease status. A lifelong occupational history was obtained, including all jobs held for at least 1 year (worktask, department, and name of company). No specific exposures were asked, but follow-up questions were triggered for certain jobs. [See Tinnerberg et al (27) for the details.] Information on extra jobs held for at least 1 year was collected in the same way as for the regular job. A broad range of hobby activities were explicitly asked for, together with questions about duration and average hours spent weekly in each activity. Furthermore, questions were asked about regular use of hair dye, smoking habits (smoking type, duration, and average consumption), and medical treatments preceding the time of the case diagnosis, focusing on chemo- or radiotherapy (including treatment with isotopes).

\section{Assessment of occupational and hobby exposures}

For a broad range of occupational and hobby exposures (table 2), individual exposure assessments were performed by one of three occupational hygienists, on the basis of the structured telephone interviews made by the occupational health nurses. The occupational hygienists were unaware of the case or referent status. The assessments for both the cases and referents were restricted to exposure periods of at least 1 year during the 20 years before the case diagnosis. One of the hygienists (HW) supervised the assessments.

Quantitative definitions of the different exposure intensity categories (low, moderate, and high) were used in the assessments of average intensities for organic solvents, benzene, and EMF. For organic solvents, these categories corresponded to $1-5 \%,>5-15 \%$, and $>15 \%$, respectively, of the recent Swedish occupational exposure limits. For benzene, the corresponding categories were $0.05-0.2 \mathrm{mg} / \mathrm{m}^{3},>0.2-0.5 \mathrm{mg} / \mathrm{m}^{3}$, and $>0.5 \mathrm{mg} / \mathrm{m}^{3}$. Exposure to EMF was classified according to 8-hour arithmetic averages reported for different occupations (28), with the following categories: 0.23$0.30 \mu \mathrm{T},>0.30-0.50 \mu \mathrm{T}$, and $>0.50 \mu \mathrm{T}$. For all other occupational exposures, the exposure intensity categories were demarcated by examples of occupations or tasks (27). Exposures to cattle or poultry (ie, animal dust) and fresh meat were considered proxy variables for exposure to animal-borne viruses. The main occupation associated with such exposures was farming. The confidence in the classification of the occupational exposure was assessed (low or high confidence) according to the quality of the information on worktasks and exposures from the interviews, as well as according to the likelihood of exposure for different worktasks. For the regular personal usage of hair dye, the classification was 
Table 2. Effects of occupational or hobby exposure of at least 1-year duration $\leq 20$ years before the case diagnosis on the risk of myelodysplastic syndromes. ( $\mathrm{OR}=$ odds ratio, $95 \% \mathrm{Cl}=95 \%$ confidence interval, $\mathrm{BMF}=$ extremely low-frequency magnetic fields)

\begin{tabular}{|c|c|c|c|c|c|c|c|c|}
\hline \multirow[t]{2}{*}{ Exposure } & \multicolumn{3}{|c|}{ Cases (N) } & \multicolumn{3}{|c|}{ Referents $(\mathrm{N})$} & \multirow[t]{2}{*}{ OR } & \multirow[t]{2}{*}{$95 \% \mathrm{Cl}^{\circ}$} \\
\hline & Exposed & Unexposed & Uncertain & Exposed & Unexposed & Uncertain & & \\
\hline Organic solvents & 65 & 218 & 47 & 56 & 218 & 63 & 1.4 & $0.86-2.2$ \\
\hline Hobby or low & 57 & & . & 40 & . & . & 1.6 & $0.96-2.7$ \\
\hline Moderate or high & 8 & & $\cdot$ & 16 & $\cdot$ & . & 0.76 & $0.31-1.9$ \\
\hline Benzene & 29 & 284 & 17 & 30 & 280 & 27 & 0.95 & $0.54-1.7$ \\
\hline Chlorinated organic solvents & 10 & 296 & 24 & 12 & 292 & 33 & 0.80 & $0.33-1.9$ \\
\hline Gasoline and diesel fuel & 61 & 261 & 8 & 56 & 263 & 18 & 1.0 & $0.63-1.6$ \\
\hline Gasoline or diesel exhaust & 64 & 256 & 10 & 56 & 248 & 33 & 1.1 & $0.68-1.7$ \\
\hline Pesticides & 41 & 271 & 18 & 42 & 260 & 35 & 0.82 & $0.50-1.4$ \\
\hline Fresh meat or cattle or poultry & 54 & 271 & 5 & 53 & 274 & 10 & 1.0 & $0.64-1.5$ \\
\hline Fresh wood & 32 & 294 & 4 & 38 & 287 & 12 & 0.80 & $0.46-1.4$ \\
\hline EMFb & 76 & 221 & 33 & 61 & 241 & 35 & 1.4 & $0.87-2.2$ \\
\hline Low & 33 & & & 35 & . & . & 1.0 & $0.59-1.8$ \\
\hline Moderate & 25 & & & 18 & . & . & 1.6 & $0.79-3.3$ \\
\hline High & 18 & $\cdot$ & . & 8 & . & . & $2.6^{c}$ & $1.0-6.2$ \\
\hline Regular personal use of hair dye & 47 & 273 & 10 & 40 & 290 & 7 & 1.5 & $0.87-2.5$ \\
\hline Fair or henna & 10 & . & . & 11 & . & & 0.98 & $0.35-2.8$ \\
\hline Dark & 31 & . & . & 25 & & & 1.5 & $0.87-2.8$ \\
\hline Unknown & 6 & & & 4 & . & . & 1.8 & $0.45-7.5$ \\
\hline
\end{tabular}

a OR and 95\% Cl obtained from conditional logistic regression (case referent sets matched for gender, age and county of residence).

${ }^{b}$ Only occupational exposure was assessed.

c Test for trend: $\mathrm{P}=0.03$.

directly based on the specific questions of the interview. The number of hairdressers was too few to permit further investigation. Hobby exposure was assessed for all occupational agents, except EMF, ionizing radiation, and cytostatics.

\section{Smoking and treatment with chemo- or radiotherapy}

For the purpose of evaluating potential confounding and effect modification, smoking habits and previous medical treatments were classified. According to the questions regarding smoking, the participants were classified as smokers if they had smoked at least one cigarette a day [or an equivalent amount for other smoking types (29)] for at least 1 year during the 20 years before the diagnosis of the case. In addition, cumulative smoking dose (pack-years) was used for confounder adjustment in some of the analyses. MDS patients who, according to the interview or the medical record, had undergone chemotherapy or radiotherapy (including treatment with isotopes) at some time during the 20 years preceding the year of diagnosis or at an unknown time were classified as secondary cases $(\mathrm{N}=56)$. For the referents, the history of chemo- or radiotherapy was based on interview information only.

\section{Statistics}

Effect estimates were obtained by conditional logistic regression (30) using EGRET (epidemiologic graphics, estimation and testing) software (Cytel Software Corporation, Cambridge, MA, USA). Matched sets with identical values for all matching factors were combined for efficiency reasons. So that all the data could be used, sets with only one case or one referent ( $8 \%$ of all sets) were added to already complete sets, fulfilling the matching criteria as much as possible. Using unconditional rather than conditional logistic regression, stratified for the two matching factors (gender and age) that proved to be of importance, only altered the effect estimates marginally, and the results are therefore not presented. When testing trends, we employed Wald's test of $\beta=0$, for which $\beta$ denotes the logistic regression coefficient for the exposure intensity as an untransformed continuous variable [provided that data were fairly consistent with such a model (31)]. Biological interaction is the most appropriately evaluated as a departure from the additivity of effects (32). Thus synergistic interaction, defined as a positive departure from additivity, was evaluated by calculating relative excess risk due to interaction (33). We have presented results from detailed analyses with regard to exposure intensity, karyotype, and morphology only for agents with a tendency towards an increased overall relative risk.

In order to reduce exposure misclassification in the individual-level analysis of occupational exposures, we used only exposure assessments with high confidence. The participants were classified as unexposed for a particular occupational agent only if they were unexposed with high confidence during the entire assessment period. The participants were classified as exposed if they were exposed with high confidence for at least 1 year 
during the assessment period. Those who could not be classified as exposed or unexposed were excluded from the analyses (table 2). Less restrictive approaches did not substantially change the results and have not been presented. Hobby exposures were included in the "low" occupational exposure categories in the analyses combining occupational and hobby exposure.

We tried to evaluate the impact of selective participation on the risk estimates associated with EMF exposure by using the procedure described by Björk et al (34). In short, data on occupational titles were obtained for both the participants and nonparticipants from the national Swedish censuses for 1960 and for every 5th year during the period 1970-1990. With these registry data, we used a Finnish job-exposure matrix (35) to assess the probability of occupational exposure to EMF above $0.30 \mu \mathrm{T}$ (moderate or high intensity) for each study subject. The association between the odds ratio and the exposure probabilities was estimated using conditional binary regression in a linear risk model $(36,37)$.

\section{Results}

\section{All myelodysplastic syndromes}

An association with intensity of exposure to EMF was observed (test for trend $\mathrm{P}=0.03$ ) (table 2). Effects for different strata of duration of exposure to EMF were similar [1-7 years: odds ratio (OR) $1.7,95 \%$ confidence interval (95\% CI) $0.78-3.5$; 8-14 years: OR $1.5,95 \%$ CI $0.73-2.9$; $15-20$ years: OR $1.4,95 \%$ CI $0.80-2.5$; not in tables]. A nonsignificant overall association with organic solvents was found that was inconsistent with respect to the intensity of exposure. Moreover, the duration of exposure to organic solvents showed no clear effect $(1-7$ years: OR $0.84,95 \%$ CI $0.36-2.0 ; 8-14$ years: OR $1.5,95 \%$ CI $0.68-3.1 ; 15-20$ years: OR 1.2 , 95\% CI 0.66-2.0; not in tables). Regular personal use of hair dye was associated with a moderately, but not significantly, increased risk. Most of the regular users were women $(95 \%)$, and the main use was dark colors. We had no data on the frequency of hair dye use, and the data on duration were incomplete (43\% missing). This lack of information hampered further investigation. The odds ratios for the other investigated occupational and hobby exposures were close to unity and without any indication of an association with intensity of exposure, a finding not altered when potential confounding from smoking and previous medical treatment was adjusted for. In particular, no association with potential exposures to animal-borne viruses (fresh meat, cattle, or poultry) was discerned. Furthermore, the participants active as farmers or farmhands during the 20 years before the MDS diagnosis had an odds ratio for MDS that was below unity (OR $0.53,95 \%$ CI $0.35-0.81 ; 55$ exposed cases; 85 exposed referents; not in tables). Adjustment for smoking and previous medical treatment did not change this odds ratio noticeably. The participants occupationally exposed to cytostatics and ionizing radiation were too few to permit analysis. Further analyses of risk for MDS stratified by clonal chromosome aberrations or morphological subgroup are presented only for the exposures for which the overall analyses indicated an association with MDS.

\section{Normal versus abnormal karyotype}

The association between organic solvents and MDS with or without karyotypic abnormalities was not more consistent than with MDS overall (table 3). The suggested

Table 3. Effects of exposure to organic (aromatic) solvents, extremely low-frequency magnetic fields (日MF), and personal hair dye use of at least 1-year duration $\leq 20$ years before the case diagnosis on the risk of myelodysplastic syndromes (MDS) with and without clonal chromosome aberrations. (Exp=exposed, Unex =unexposed, Uncer = uncertain, OR=odds ratio, $95 \% \mathrm{Cl}=95 \%$ confidence interval)

\begin{tabular}{|c|c|c|c|c|c|c|c|c|c|c|c|c|c|c|c|c|}
\hline \multirow[t]{3}{*}{ Exposure } & \multicolumn{8}{|c|}{ MDS with clonal chromosome aberrations } & \multicolumn{8}{|c|}{ MDS with a normal karyotype } \\
\hline & \multicolumn{3}{|c|}{ Cases (N) } & \multicolumn{3}{|c|}{ Referents $(\mathrm{N})$} & \multirow[t]{2}{*}{ OR } & \multirow[t]{2}{*}{$95 \% \mathrm{Cl}^{\mathrm{a}}$} & \multicolumn{3}{|c|}{ Cases $(\mathrm{N})$} & \multicolumn{3}{|c|}{ Referents $(\mathrm{N})$} & \multirow[t]{2}{*}{ OR } & \multirow[t]{2}{*}{$95 \% \mathrm{Cl}^{\mathrm{a}}$} \\
\hline & Exp & Unex & Uncer & Exp & Unex & Uncer & & & Exp & Unex & Uncer & Exp & Unex & Uncer & & \\
\hline Organic solvents & 30 & 114 & 24 & 23 & 115 & 32 & 1.4 & $0.75-2.7$ & 35 & 104 & 23 & 33 & 103 & 31 & 1.2 & $0.63-2.5$ \\
\hline Leisure-time or low & 26 & . & . & 18 & . & . & 1.5 & $0.77-3.0$ & 31 & . & . & 22 & . & . & 1.6 & $0.73-3.3$ \\
\hline Moderate or high & 4 & . & . & 5 & . & . & 0.97 & $0.25-3.8$ & 4 & . & . & 11 & . & . & 0.61 & $0.18-2.1$ \\
\hline $\mathrm{BMF}^{\mathrm{b}}$ & 30 & 124 & 14 & 30 & 124 & 16 & 1.0 & $0.53-1.9$ & 46 & 97 & 19 & 31 & 117 & 19 & 2.0 & $1.0-4.0$ \\
\hline Low & 12 & . & . & 16 & . & . & 0.68 & $0.28-1.7$ & 21 & . & . & 19 & . & . & 1.6 & $0.75-3.5$ \\
\hline Moderate & 12 & . & . & 10 & . & . & 1.3 & $0.50-3.5$ & 13 & . & . & 8 & . & . & 2.4 & $0.81-7.1$ \\
\hline High & 6 & . & . & 4 & . & . & 1.5 & $0.40-5.9$ & 12 & . & . & 4 & & & $4.3^{c}$ & 1.3-15 \\
\hline Hair dye use & 27 & 134 & 7 & 29 & 138 & 3 & 1.2 & $0.58-2.5$ & 20 & 139 & 3 & 11 & 152 & 4 & 1.8 & $0.85-3.8$ \\
\hline
\end{tabular}

a OR and $95 \% \mathrm{Cl}$ obtained from conditional logistic regression (case referent sets matched for gender, age and county of residence).

b Only occupational exposure was assessed.

c Test for trend, $\mathrm{P}=0.01$. 
risk from regular personal usage of hair dye was higher for cytogenetically normal MDS than for cytogenetically abnormal MDS, but both confidence intervals included unity. The estimate for normal karyotype did not change noticeably after further adjustment for smoking, exposure to benzene, and previous medical treatment. The corresponding adjusted estimate for abnormal MDS was below unity. Exposure to EMF was only significantly associated with an increased risk for MDS with normal karyotype. An exposure-response association was indicated with intensity of exposure (test for trend: $\mathrm{P}=0.01$ ). This trend did not change when exposure to benzene and previous radio- or chemotherapy was adjusted for. For MDS with a normal karyotype, the odds ratio associated with exposure to EMF was elevated in the broad group of participants unexposed to organic solvents (OR 4.3 , 95\% CI 0.92-20; not in tables), whereas the corresponding effect estimate in the smaller group of participants exposed to organic solvents was imprecise and showed no effect (OR 0.67, 95\% CI 0.11-4.0; not in tables). A stratified analysis suggested a synergistic interaction between intensity of exposure to EMF and smoking with regard to risk for MDS with normal karyotype, although an additivity of effects could not be ruled out $(\mathrm{P}=0.30)$ (table 4). Adjusting for differences in cumulative smoking dose between the participants unexposed and exposed to EMF did not alter the suggested synergism (not in tables). The pattern for MDS with a normal karyotype was inconclusive with regard to duration of exposure to EMF, with a significantly increased risk for the long durations (15-20 years: OR 2.6, 95\% CI 1.1-6.1) and similar estimated effects but with wider confidence intervals for shorter durations
(1-7 years: OR $2.3,95 \%$ CI $0.80-6.7 ; 8-14$ years: OR $1.7,95 \%$ CI $0.66-4.5$; not in tables).

\section{Karyotypic subgroups}

No distinct pattern was found between exposure to the different agents of interest and the karyotypic prognostic subgroup or number of abnormalities. In particular, the estimated odds ratios for MDS with a complex karyotype (49 cases), associated with a poor prognosis, were generally close to unity. The effect estimates for MDS with specific clonal chromosome aberrations were imprecise. No significantly increased risks for MDS with specific abnormalities of chromosomes 3, 5, 7, 8, or 12 (for definitions, see the Methods section) were observed for any exposure. Among these nonsignificant findings, a possibly stronger effect from exposure to EMF that was indicated for losses involving chromosome 3 is worth noting. Five of the 10 cases with losses involving chromosome 3 were exposed to EMF compared with one of the 10 corresponding referents (OR 16, 95\% CI 0.90-270, unconditional logistic regression, stratified for gender and age in three broad categories). For organic solvents, the highest odds ratio was observed for trisomy 8 as the sole abnormality (OR 1.7, 95\% CI 0.40-7.0).

\section{Morphologic subgroups}

The effect estimates for all the investigated agents were essentially nondifferential with respect to their morphologic subgroup. However, a possibly stronger effect of EMF was suggested for chronic myelomonocytic leukemia (OR 2.5, 95\% CI 0.78-8.0, 58 cases),

Table 4. Effects of occupational exposure to extremely low-frequency magnetic fields (日MF) of at least 1-year duration $\leq 20$ years before the case diagnosis on the risk for myelodysplastic syndromes (MDS) with and without clonal chromosome aberrations, as modified by smoking.

\begin{tabular}{|c|c|c|c|c|c|c|c|c|}
\hline \multirow[t]{2}{*}{ Smoking status ${ }^{a}$} & \multicolumn{4}{|c|}{ MDS with clonal chromosome aberrations } & \multicolumn{4}{|c|}{ MDS with a normal karyotype } \\
\hline & Cases (N) & Referents (N) & OR & $95 \% \mathrm{Cl}^{\mathrm{b}}$ & Cases $(\mathrm{N})$ & Referents (N) & $\mathrm{OR}$ & $95 \% \mathrm{Cl}^{\mathrm{b}}$ \\
\hline \multicolumn{9}{|l|}{ Nonsmokers } \\
\hline No EMF exposure & 64 & 77 & 1.0 & $\cdot$ & 54 & 74 & 1.0 & . \\
\hline Any 日MF exposure & 9 & 14 & 1.1 & $0.37-3.0$ & 18 & 18 & 1.8 & $0.69-4.7$ \\
\hline Low & 5 & 7 & . & . & 10 & 10 & . & . \\
\hline Moderate & 3 & 5 & . & . & 3 & 4 & . & . \\
\hline High & 1 & 2 & . & . & 5 & 4 & . & . \\
\hline Uncertain EMF exposure & 9 & 9 & . & . & 8 & 10 & . & . \\
\hline \multicolumn{9}{|l|}{ Smokers } \\
\hline No 日MF exposure & 56 & 45 & 2.1 & $1.0-4.1$ & 42 & 42 & 2.1 & $1.1-4.1$ \\
\hline Any 日MF exposure & 21 & 15 & 1.7 & $0.70-4.3$ & 28 & 13 & $5.2^{c}$ & $1.9-14$ \\
\hline Low & 7 & 8 & $\cdot$ & $\cdot$ & 11 & 9 & $\cdot$ & $\cdot$ \\
\hline Moderate & 9 & 5 & . & . & 10 & 4 & . & . \\
\hline High & 5 & 2 & . & . & 7 & 0 & . & . \\
\hline Uncertain 日MF exposure & 5 & 6 & . & . & 10 & 6 & . & . \\
\hline
\end{tabular}

a Six cases and eight referents with unknown smoking habits in the 20-year time span before case diagnosis were excluded.

b OR and $95 \% \mathrm{Cl}$ obtained from a conditional logistic regression (case-referent sets matched for gender, age and county of residence).

${ }^{c}$ Relative excess risk due to interaction for MDS with a normal karyotype $=5.2-1.8-(2.1-1.0)=2.3(95 \% \mathrm{Cl}=-2.0-6.6, \mathrm{P}=0.30)$. 
especially for cases with a normal karyotype (OR 3.5, 95\% CI 0.73-17).

\section{Impact of selective participation}

According to the interview data and the individual exposure assessments, the odds ratio for MDS with a normal karyotype in association with EMF exposure at a moderate or high intensity was 3.1 (95\% CI 1.2-7.9; not in tables). When calculated using the participants' data from the census and the job-exposure matrix, the corresponding odds ratio was lower (OR 1.7, 95\% CI 0.55 5.2). When the nonparticipants' data from the census and the job-exposure matrix were included, the odds ratio decreased further (OR 1.2, 95\% CI 0.52-2.9).

\section{Discussion}

Occupational and hobby exposures to known or suspected genotoxic agents in the general Swedish population from around 1970 onwards were, contrary to the hypothesis, not generally associated with cytogenetically abnormal MDS. High and moderate exposure intensities were, however, rare for many of these agents. Consequently, despite the relatively large study size, the statistical power to detect associations with moderate-tohigh exposure levels of specific agents was low. Only 8 cases and 16 referents were exposed to $>5 \%$ of the current occupational limits for organic solvents (corresponding to, for example, a white spirit concentration of $>2.5 \mathrm{ppm}$ ). Thus our results do not exclude the possibility that moderate-to-high exposures to occupational agents are risk factors for MDS with abnormal karyotype, but they do imply that the population attributable risk in southern Sweden in association with such exposures is likely to be low. Contrary to the findings of an Italian study (21), our analyses by morphological subgroup did not indicate that subgroups with a high transformation rate to acute leukemia (implying a poor prognosis) were generally associated with exposures to potentially genotoxic agents.

Exposure to EMF has been suggested to have a tumor promoter or co-promoter effect rather than a direct mutagenic effect $(38,39)$, but numerous experimental animal studies have failed to show an association between EMF and leukemogenesis (38). Most of the subjects exposed to EMF in our study had a long duration of exposure within the investigated 20-year time span (median duration 14 years for both the both cases and the referents; not in results), and this long duration of exposure made it impossible to determine the effect of EMF in more narrow time spans. Increased in vitro cell survival as a result of EMF exposure has been reported starting at $600 \mu \mathrm{T}(40)$. Our moderate exposure intensity level corresponded to $>0.3-0.5 \mu \mathrm{T}$ as an 8-hour average, and high intensity was equivalent to $>0.5 \mu \mathrm{T}$ (maximum $2.5 \mu \mathrm{T}$ ), both of which are far from the effect levels established in in vitro assays. However, peak exposures may be two orders of magnitude higher than the 8-hour averages (28) and the approach effect levels in in vitro assays. The results of epidemiologic studies show evidence of an association between residential EMF exposure above $0.40 \mu \mathrm{T}$ and childhood leukemia (41), but the association with adult leukemia is questionable (42). In our study, we found an association between occupational exposure to EMF at moderate or high intensities and cytogenetically normal MDS, possibly stronger for chronic myelomonocytic leukemia. Typical occupations classified as exposed to EMF at a moderate or high intensity were welders, sheetmetal workers, turners, millers, tool makers, forestry workers, railway workers, repairmen, and oven workers-all occupations dominated by men. The association with exposure to EMF could not be explained by simultaneous exposure to organic solvents, including benzene. A large study in the United Kingdom (400 MDS cases) showed some association with occupational exposure to EMF at power-line frequency (OR 1.9, 95\% CI $0.75-4.8$ for the highest exposure category) and radio frequency electromagnetic fields (OR 3.0, 95\% CI 0.75-14), but this association was not clearly differential with regard to karyotype $(15,24)$. In settings identical to those of our study, we found some evidence of an association between occupational exposure to EMF and chronic myeloid leukemia (34), whereas no association with acute myeloid leukemia was discerned (43). For tobacco smoking, associations with MDS overall, as well as specifically with MDS with chromosome 7 aberrations, have been reported previously for our case series (10). In our study, a synergistic interaction between EMF and smoking was indicated for MDS with a normal karyotype (table 4), but it was not significant. A specific association between EMF and MDS with monosomy 3/ deletion of chromosome arm $3 p$ was indicated, but the effect estimate was imprecise and was not supported by an overall association between EMF and MDS with an abnormal karyotype.

In a Chinese study on benzene, in which an excess risk of MDS was observed, the mean exposure intensity was $22.5 \mathrm{ppm}(9,44)$. In our study, which showed no association with benzene exposure, most of the subjects were exposed only to $<0.07 \mathrm{ppm}$. These results are therefore not necessarily contradictory because the studies represent different parts of the exposure-response curve. For organic solvents as a group, we have previously reported an association with acute myeloid leukemia which was stronger for acute myeloid leukemia with trisomy 8 than for the disease overall (43). Although our 
study showed no consistent association with organic solvents, it is noteworthy that the highest odds ratio was found for MDS with trisomy 8 as the sole abnormality, albeit with a wide confidence interval.

Several hair colorants are mutagenic in bacteriabased assays, and work as a hairdresser or barber has been classified as probably carcinogenic to humans, mainly based on a consistently increased risk for bladder cancer (45). However, the evidence for an association between personal usage of hair dye and MDS is weak (20). If anything, our data suggest an association with MDS with a normal karyotype. Unfortunately, the effects of duration or frequency of use could not be evaluated. A decreased risk for MDS among farmers and farmhands was observed. This finding was somewhat unexpected, but it is in agreement with findings reported in the United Kingdom (15) and the United States (46) while, in a French study, agricultural work was associated with an increased risk for MDS (13). It is possible that different factors, positively as well as negatively associated with risk for MDS, are present in farming life and that the distribution of these factors vary substantially across countries.

All referrals for cytogenetic investigations are made within the Swedish public health system, which essentially rules out selection bias among cases due to socioeconomic factors. However, cases diagnosed for a patient with a high age, when curative intended therapy is less frequent, are likely to be underrepresented. The average number of jobs reported was lower when the information was obtained from next-of-kin than when obtained from the person him- or herself, and, because of the high case mortality, this situation was reflected in fewer jobs being reported for the cases than for the referents (mean number of jobs reported 2.9 and 3.5, respectively). A similar, but less pronounced, pattern was observed for hobbies. Thus differential reporting of exposures among the cases and referents may have biased our results towards unity, for example, by fewer reported occupations or hobbies giving less probability of being classified as exposed to the investigated agents. Restricting the analyses to the cases and referents interviewed in person left few matched pairs and introduced selection with regard to year of diagnosis, age, and prognosis. Such an analysis of the effect of EMF on the risk for MDS with normal karyotype implied substantially reduced precision (OR 1.5, 95\% CI 0.25-9.0). Including respondent status as a covariate in the conditional logistic regression model also implied considerable loss of precision. Moreover, the validity in adjusting for a factor that is mainly a consequence of disease can be questioned (47).

The participation rate of our study was high among the eligible cases (85\%), but lower among the referents $(60 \%)$. The odds ratio associated with EMF according to data from the census and job-exposure matrix decreased when the data on the nonparticipants were included, and this decrease may indicate that selective participation in the interviews resulted in bias away from the null for our risk estimates in association with EMF exposure. However, both the census data and the EMF exposure data from the job-exposure matrix are crude, and thus no firm conclusion about the presence of participation bias in our data can be drawn.

The classification of EMF intensity was largely based on the average intensities for various occupational groups as reported by Floderus et al (28). The number of personal measurements in each occupational group was limited and showed large variations in intensity. Furthermore, a reassessment of the exposure for a sample of subjects from our study, as well as from studies of other hematological malignancies in southern Sweden, showed only moderate interrater reliability for exposure to EMF (Cohen's kappa 0.53). [For details, see Tinnerberg et al (27).] Thus some misclassification of the EMF intensity is likely to be present. When categories are formed from underlying continuous exposure levels, differential misclassification may arise even if the exposure assessment is blind, if both the disease risk and the probability of misclassification vary within an exposure category $(48,49)$. Differential misclassification may bias the expected odds ratio either toward or away from the null value. We had no information on alcohol consumption, for which an elevated risk has been reported $(11,50)$, although not confirmed in a recent study (18). However, a close association has been observed between smoking and alcohol consumption (51), and it is thus likely that we have indirectly accounted for such potential confounding by adjusting for smoking. Adjustments for previous medical treatment did not change the relative estimates noticeably, and therefore no confounding was indicated.

In conclusion, cytogenetically abnormal MDS were, in general, not associated with occupational or hobby exposure to known or suspected genotoxic agents. Our data suggest an association between occupational exposure to EMF and MDS with a normal karyotype. Biases due to differential information quality and selective participation cannot be ruled out.

\section{Acknowledgments}

Timo Kauppinen provided access to the Finnish job-exposure matrix. Siv Hansson, Ingegärd Nilsson, and Siv Nilsson performed the interviews. Ulrika Wallin administered the interviews and computerized the data together with Gudrun Persson. Asta Persson and Gunnel Nilsson retrieved the medical records. Per-Arne 
Hambert assisted with the hygienic assessment of the interviews.

This project was supported by grants from the Swedish Council for Work Life Research, the Swedish Cancer Society, the Medical Faculty of Lund University, Gunnar, Arvid and Elisabeth Nilsson's Research Foundation, and the PREEM Research Foundation.

\section{References}

1. Aul C, Bowen DT, Yoshida Y. Pathogenesis, etiology and epidemiology of myelodysplastic syndromes. Haematologica 1998;83:71-86.

2. Bennett JM, Catovsky D, Daniel MT, Flandrin G, Galton DAG, Gralnick HR, et al. The French-American-British (FAB) Cooperative Group: proposals for the classification of the myelodysplastic syndromes. Br J Haematol 1982;51:189-99.

3. Greenberg P, Cox C, LeBeau M, Fenaux P, Morel P, Sanz G, et al. International scoring system for evaluating prognosis in myelodysplastic syndromes. Blood 1997;89:2079-88.

4. Williamson PJ, Kruger AR, Reynolds PJ, Hamblin TJ, Oscier DG. Establishing the incidence of myelodysplastic syndrome. Br J Haematol 1994;87:743-5.

5. Aul C, Gattermann N, Schneider W. Epidemiological and etiological aspects of myelodysplastic syndromes. Leuk Lymphoma 1995;16:247-62.

6. Rådlund A, Thiede T, Hansen S, Carlsson M, Engquist L. Incidence of myelodysplastic syndromes in a Swedish population. Eur J Haematol 1995;54:153-6.

7. Pedersen-Bjergaard J, Pedersen M, Roulston D, Philip P. Different genetic pathways in leukemogenesis for patients presenting with therapy-related myelodysplasia and therapyrelated acute myeloid leukemia. Blood 1995;86:3542-52.

8. Johansson B, Mertens F, Heim S, Kristoffersson U, Mitelman F. Cytogenetics of secondary myelodysplasia (sMDS) and acute nonlymphocytic leukemia (sANLL). Eur J Haematol 1991;47:17-27.

9. Hayes RB, Yin SN, Dosemeci M, Li GL, Wacholder S, Travis $\mathrm{LB}$, et al. Benzene and the dose-related incidence of hematologic neoplasms in China. J Natl Cancer Inst 1997;89:106571.

10. Björk J, Albin M, Mauritzson N, Strömberg U, Johansson B, Hagmar L. Smoking and myelodysplastic syndromes. Epidemiology 2000;11:285-91.

11. Ido M, Nagata C, Kawakami N, Shimizu H, Yoshida Y, Nomura $\mathrm{T}$, et al. A case-control study of myelodysplastic syndromes among Japanese men and women. Leuk Res 1996;20:727-31.

12. Pasqualetti P, Festuccia V, Acitelli P, Collacciani A, Giusti A, Casale R. Tobacco smoking and risk of haematological malignancies in adults: a case-control study. Br J Haematol 1997;97:659-62.

13. Nisse C, Haguenoer JM, Grandbastien B, Preudhomme C, Fontaine B, Brillet JM, et al. Occupational and environmental risk factors of the myelodysplastic syndromes in the North of France. Br J Haematol 2001;112:927-35.

14 Brown LM, Gibson R, Blair A, Burmeister LF, Schuman LM, Cantor KP, et al. Smoking and risk of leukemia. Am J Epidemiol 1992;135:763-8.

15. West RR, Stafford DA, Farrow A, Jacobs A. Occupational and environmental exposures and myelodysplasia: a case-control study. Leuk Res 1995;19:127-39.

16. Crane M, Keating M. Exposure histories in acute nonlymphocytic leukemia patients with a prior preleukemic condition. Cancer 1991;67:2211-4.

17. Ciccone G, Mirabelli D, Levis A, Gavarotti P, Rege Cambrin $\mathrm{G}$, Davico L, et al. Myeloid leukemias and myelodysplastic syndromes: chemical exposure, histologic subtype and cytogenetics in a case-control study. Cancer Genet Cytogenet 1993;68:135-9.

18. Nagata C, Shimizu H, Hirashima K, Kakishita E, Fujimura K, Niho Y, et al. Hair dye use and occupational exposure to organic solvents as risk factors for myelodysplastic syndrome. Leuk Res 1999;23:57-62.

19. Cantor KP, Blair A, Everett G, VanLier S, Burmeister L, Dick FR, et al. Hair dye use and risk of leukemia and lymphoma. Am J Public Health 1988;78:570-1.

20. Correa A, Mohan A, Jackson L, Perry H, Helzlsouer K. Use of hair dyes, hematopoietic neoplasms, and lymphomas: a literature review, I: leukemias and myelodysplastic syndromes. Cancer Invest 2000;18:366-80.

21. Rigolin GM, Cuneo A, Roberti MG, Bardi A, Bigoni R, Piva $\mathrm{N}$, et al. Exposure to myelotoxic agents and myelodysplasia: case-control study and correlation with clinicobiological findings. Br J Haematol 1998;103:189-97.

22. Farrow A, Jacobs A, West RR. Myelodysplasia, chemical exposure, and other environmental factors. Leukemia 1989;3:33-5.

23. Blair A, Zheng T, Linos A, Stewart, PA, Zhang YW, Cantor KP. Occupation and leukemia: a population-based case-control study in Iowa and Minnesota. Am J Ind Med 2001;40:314.

24. West RR, Stafford DA, White AD, Bowen DT, Padua RA. Cytogenetic abnormalities in the myelodysplastic syndromes and occupational or environmental exposure. Blood 2000;95:2093-7.

25. Mitelman F, editor. An international system for human cytogenetic nomenclature, Basel: S Karger; 1995.

26. Mauritzson N, Johansson B, Albin M, Billström R, Ahlgren T, Mikoczy Z, et al. A single-center population-based consecutive series of 1500 cytogenetically investigated adult hematologic malignancies: karyotypic features in relation to morphology, age and gender. Eur J Haematol 1999;62:95-102.

27. Tinnerberg H, Björk J, Welinder H. Evaluation of occupational and leisure time exposure assessment in a population-based case control study on leukemia. Int Arch Occup Environ Health 2001;74:533-40.

28. Floderus B, Persson T, Stenlund C. Magnetic-field exposures in the workplace: reference distribution and exposures in occupational groups. Int J Occup Environ Health 1996;2:226-38.

29. Doll R, Peto R. Mortality in relation to smoking: 20 years' observations on male British doctors. Br Med J 1976;2:152536.

30. Hosmer DW, Lemeshow S. Applied logistic regression. New York: Wiley; 1989.

31. Maclure M, Greenland S. Tests for trend and dose response: misinterpretations and alternatives. Am J Epidemiol 1992;135:96-104.

32. Greenland S, Rothman KJ. Concepts of interaction. In: Rothman K, Greenland S, editors. Modern epidemiology. 2nd ed. Philadelphia (PA): Lippincott-Raven; 1998. p 329-42.

33. Hosmer DW, Lemeshow S. Confidence interval estimation of interaction. Epidemiology 1992;3:452-6.

34. Björk J, Albin M, Welinder H, Tinnerberg H, Mauritzson N, 
Kauppinen T, et al. Are occupational, hobby, or lifestyle exposures associated with Philadelphia chromosome-positive chronic myeloid leukemia? Occup Environ Med 2001;58:722-7.

35. Kauppinen T, Toikkanen J, Pukkala E. From cross-tabulations to multipurpose exposure information systems: a new jobexposure matrix. Am J Ind Med 1998;33:409-17.

36. Bouyer J, Hémon D. Comparison of three methods of estimating odds ratios from a job exposure matrix in occupational case-control studies. Am J Epidemiol 1993;137:472-81.

37. Björk J, Strömberg U. Effects of systematic exposure assessment errors in partially ecologic case-control studies. Int $\mathrm{J}$ Epidemiol 2002;31:154-60.

38. Portier CJ, Wolfe MS. Assessment of health effects from exposure to power-line frequency and magnetic fields: working group report. Research Triangle Park (NC): National Institute of Environmental Health Sciences; 1998.

39. Morandi MA, Pak CM, Caren RP, Caren LD. Lack of an EMF-induced genotoxic effect in the Ames assay. Life Sci 1996;59:263-71.

40. Fanelli C, Coppola S, Barone R, Colussi C, Gualandi G, Volpe $P$, et al. Magnetic fields increase cell survival by inhibiting apoptosis via modulation of $\mathrm{Ca} 2+$ influx. FASEB J 1999;13:95-102.

41. Ahlbom A, Day N, Feychting M, Roman E, Skinner J, Dockerty $\mathrm{J}$, et al. A pooled analysis of magnetic fields and childhood leukaemia. Br J Cancer 2000;83:692-8.

42. Kheifets LI, Afifi AA, Buffler PA, Zhang ZW, Matkin CC. Occupational electric and magnetic field exposure and leukemia: a meta-analysis. J Occup Environ Med 1997;39:1074-91.

43. Albin M, Björk J, Welinder H, Tinnerberg H, Mauritzson N, Johansson B, et al. Acute myeloid leukemia and clonal chro- mosome aberrations in relation to past exposure to organic solvents. Scand J Work Environ Health 2000;26:482-91.

44. Yin SN, Hayes RB, Linet MS, Li GL, Dosemeci M, Travis LB, et al. A cohort study of cancer among benzene-exposed workers in China: overall results. Am J Ind Med 1996;29:22735.

45. International Agency for Research on Cancer (IARC). Occupational exposures of hairdressers and barbers and personal use of hair colurants; some hair dyes, cosmetic colourants, industrial dyestuffs and aromatic amines. Lyon: IARC; 1993.

46 Brown LM, Blair A, Gibson R, Everett GD, Cantor KP, Schuman LM, et al. Pesticide exposures and other agricultural risk factors for leukemia among men in Iowa and Minnesota. Cancer Res 1990;50:6585-91.

47. Wacholder S, Silverman DT, McLaughlin JK, Mandel JS. Selection of controls in case-control studies, III: design options. Am J Epidemiol 1992;135:1042-50.

48. Wacholder S, Dosemeci M, Lubin JH. Blind assignment of exposure does not always prevent differential misclassification. Am J Epidemiol 1991;134:433-7.

49. Flegal KM, Keyl PM, Nieto FJ. Differential misclassification arising from nondifferential errors in exposure measurement. Am J Epidemiol 1991;134:1233-44.

50 Brown LM, Gibson R, Burmeister LF, Schuman LM, Everett GD, Blair A. Alcohol consumption and risk of leukemia, nonHodgkin's lymphoma, and multiple myeloma. Leukemia Res 1992;16:979-84.

51. Doll R, Peto R, Wheatley K, Gray R, Sutherland I. Mortality in relation to smoking: 40 years' observations on male British doctors. BMJ 1994;309:901-11.

Received for publication: 17 January 2003 